(2)

\title{
Decreased MicroRNA-221 is Associated with High Levels of TNF- $\alpha$ in Human Adipose Tissue-Derived Mesenchymal Stem Cells From Obese Woman
}

\author{
Wen-Wen Chou ${ }^{a, b} \quad$ Yu-Ting Wang ${ }^{d}$ Yi-Chu Liao ${ }^{f, g}$ Shih-Chang Chuang c,e \\ Shen-Nien Wang ${ }^{\mathrm{c}, \mathrm{e}}$ Suh-Hang Hank Juo $\mathrm{o}^{\mathrm{a}, \mathrm{d}, \mathrm{h}}$
}

${ }^{a}$ Department of Medical Research, ${ }^{b}$ Hepatobiliary Division, Department of Internal Medicine, 'Division of Hepato-biliary-pancreatic Surgery, Department of Surgery, Kaohsiung Medical University Hospital, Kaohsiung; dDepartment of Genome Medicine, e Department of Medicine, College of Medicine, Kaohsiung Medical University, Kaohsiung; fSection of Neurology, Taichung Veterans General Hospital, Taichung; ' ${ }^{D}$ epartment of Neurology, National Yang-Ming University, School of Medicine, Taipei; hDepartment of Neurology, Kaohsiung Medical University Hospital, Kaohsiung

\section{Key Words}

hASCs $\bullet$ miR-221 $\bullet$ TNF- $\alpha \cdot$ Obesity $\bullet$ Adipocytes

\begin{abstract}
Aim: The present study aimed to investigate the regulation and involvement of miR-221 in the differentiation of human adipose tissue-derived mesenchymal stem cells (hASCs). The relationships between miR-221 and pro-inflammatory markers and adipokines were also explored. Methods: Eight adipose tissues were obtained from four obese (mean body mass index $(B M I)=31.7 \mathrm{~kg} / \mathrm{m}^{2}$ ) and four lean (mean BMI $=21.5 \mathrm{~kg} / \mathrm{m}^{2}$ ) women. $\mathrm{hASC}$ were induced to differentiate, and the related gene expression were measured in the hASC-differentiated adipocytes using real-time reverse transcriptase polymerase chain reaction (real-time RTPCR). Results: During adipogenesis, miR-221 was significantly down-regulated; furthermore, miR-221 levels were lower in hASC-differentiated adipocytes from obese subjects than in the corresponding adipocytes from lean subjects. Higher TNF- $\alpha$ mRNA levels were associated with lower levels of miR-221. In addition, the miR-221 levels in the adipocytes were inversely correlated with BMI. Conclusion: Our results support the link between miR-221 and obesity development as well as obesity related inflammatory status.
\end{abstract}


Chou et al.: Decreased MicroRNA-221 is Associated with High Levels of TNF- $\alpha$

\section{Introduction}

MicroRNAs (miRNAs) are small, non-coding RNAs that bind to their target messenger RNAs (mRNAs) to induce mRNA degradation and/or to repress protein synthesis [1]. miRNAs have been implicated in many biological processes, including cell proliferation [2], fat metabolism [2], differentiation [3], and cell death [3]. MicroRNAs have been shown to play a role in tumorigenesis [1], as well as several common diseases such as cardiovascular diseases $[4,5]$ and diabetes $[6,7]$. Recent studies have also found that miRNAs play a regulatory role in adipogenic differentiation $[8,9]$ and the development of obesity [10-12].

Adipose tissue contains adipose tissue-derived mesenchymal stem cells (ASCs) that can differentiate into various cell types including adipocytes, osteoblasts, myoblasts, and chondroblasts $[13,14]$. Adipogenesis differentiation can be assessed by intracellular lipid accumulation and the expression of adipocyte-specific genes such as the glucose transporter type 4 (GLUT4), hormone-sensitive lipase (HSL) and peroxisome proliferator activated receptor $\gamma$ (PPARG) genes [15]. Previous studies have also shown that miRNAs can influence the differentiation and the function of human ASCs (hASCs) $[16,17]$.

An increase of macrophage infiltration can be found in the adipose tissue of obese people. Low-grade, chronic inflammation further leads to insulin resistance in obese subjects $[18,19]$. Tumor necrosis factor-alpha (TNF- $\alpha$ ) is a macrophage- produced cytokine and is involved in chronic inflammation. An elevated TNF- $\alpha$ expression in the adipose tissue may contribute to metabolic dysfunction in obese subjects [20]. In addition, the plasma levels of pro-inflammatory cytokines like TNF- $\alpha$ [21], interleukin-6 (IL-6) [22] and interleukin-8 (IL-8) [23] are elevated in obese people. TNF- $\alpha$ can stimulate the secretion of inflammatory cytokines such as monocyte chemotactic protein-1 (MCP-1) [24, 25] and several adipokines including leptin [26, 27] and thrombospondin 1 (TSP1) [28, 29]. Serum levels of leptin $[30,31]$ and TSP1 [32] are elevated in obese and insulin-resistant subjects. It has been shown that miR-221 can directly bind to the 3' untranslated region (UTR) of TNF- $\alpha$ to cause its mRNA degradation [33]. According to the miRWalk database [34], the 3'-UTRs of leptin and TSP1 mRNAs were also predicted to have miR-221 binding sites. Taken together, miR-221 is likely to affect multiple downstream genes in the TNF- $\alpha$ signaling pathway in adipogenesis.

It has been reported that miR-221 is significantly down-regulated during adipogenesis in 3T3-L1 cells [10] and in human subcutaneous fat cells [35]. However, miR-221 has not been investigated in hASCs. In this study, we first aimed to clarify the role of miR-221 in hASCs adipogenic differentiation. Given that pro-inflammatory cytokines and adipokines are highly related to obesity, our second aim was to test for the influence of miR-221 on TNF- $\alpha$, IL-6, IL-8, MCP-1, leptin and TSP1.

\section{Materials and Methods}

\section{Subjects and materials}

Because miR-221 is located on the X chromosome, we only investigated the hASCs derived from women. The human visceral fat tissues were obtained from 8 women who received gallbladder surgery because of clinical needs. The fat tissues surrounding the gallbladder were isolated for the current study. These subjects did not have hyperglycemia, hyperlipidemia, high blood pressure and malignant diseases on enrollment. A $1 \times 1 \times 1 \mathrm{~cm}^{3}$ fat tissue was obtained during surgery and stored at $4^{\circ} \mathrm{C}$ immediately. All protocols involved in human subjects were approved by the Institutional Review Board of Kaohsiung Medical University Hospital (KMUH) and all participants gave their informed consent. Eight adipose tissues were obtained from women with body mass index (BMI) between 19.6 and $33.3 \mathrm{~kg} / \mathrm{m}^{2}$. We used eight different hASC samples for each experiment and performed the technical duplicate for each sample. The participants were divided into two groups and listed in the Table 1. 
Chou et al.: Decreased MicroRNA-221 is Associated with High Levels of TNF- $\alpha$

Induction of hASC differentiation and Oil Red $O$ stain

hASCs were isolated and induced to differentiate according to the methods described in our previous studies [36]. hASCs were propagated in the K-NAC medium (Keratinocyte-SFM medium, Asc 2-P $(0.2 \mathrm{mM})$, NAC ( $2 \mathrm{mM}), 5 \%$ FBS and $1 \%$ penicillin/ streptomycin). To induce cell differentiation from hASCs to adipocytes, the culture medium was shifted to adipogenic medium (DMEM with high glucose (4500 mg/L), 10\% FBS, dexamethasone $(1 \mathrm{mM})$, insulin $(0.01 \mathrm{mg} / \mathrm{ml})$, indomethacin $(0.2$ $\mathrm{mM}), 3$-isobutyl-I-methlxanthine $(0.5 \mathrm{mM}), 1 \%$ penicillin/ streptomycin and $0.5 \%$ gentamycin) after the cells were grown into confluence. The extent of adipogenic differentiation was evaluated by Oil Red 0 stain, which is an indicator of intracellular lipid accumulation. After induction of adipogenic differentiation, cells were washed in PBS, fixed for $1 \mathrm{~h}$ in $10 \%$ formalin and washed three additional times in PBS. The cells were then stained for 30 min with Oil Red 0 . The phase contrast images were photographed by a digital CCD camera equipped in a microscope. In order to quantify the lipid content in the hASC-differentiated adipocytes, $1 \mathrm{ml}$ of $100 \%$ isopropyl alcohol was added to the stained culture dish. After 5 minutes, the absorbance of the extract was assayed by an absorbance reader (BioTek Instruments, Inc, Winooski, VT) at $510 \mathrm{~nm}$ after dilution to a linear range.

\section{Total RNA extraction and real-time PCR}

Total RNA was isolated by using TRIzol reagent (Invitrogen, Carlsbad, CA, USA) and then reversely transcribed by using reverse transcriptase kits (ABI,
Table 1. Clinical data for study participants. BMI, body mass index

\begin{tabular}{cccc}
\hline & Lean $(\mathrm{n}=4)$ & Obese $(\mathrm{n}=4)$ & $\mathrm{p}$ value \\
\hline $\begin{array}{c}\text { Age (years), mean } \\
(\text { min-max })\end{array}$ & 48.8 & 32.3 & 0.0876 \\
& $(34-63)$ & $(28-34)$ & \\
& & & \\
$\begin{array}{c}\text { BMI }\left(\mathrm{kg} / \mathrm{m}^{2}\right), \text { mean } \\
(\text { min-max })\end{array}$ & 21.5 & 31.7 & 0.0005 \\
& $(19.6-23.7)$ & $(30.2-33.3)$ & \\
& & & \\
$\begin{array}{c}\text { Waist-hip ratio , mean } \\
\text { (min-max) }\end{array}$ & 0.780 & 0.853 & 0.0197 \\
\hline
\end{tabular}

Table 2.The forward and reverse primers

\begin{tabular}{|c|c|}
\hline primer & Sequence $\left(5^{\prime} \rightarrow 3^{\prime}\right)$ \\
\hline IL-8 & $\begin{array}{l}\text { Forward TTGGCAGCCTTCCTGATTTC } \\
\text { Reverse AACTTCTCCACAACCCTCTG }\end{array}$ \\
\hline MCP-1 & $\begin{array}{l}\text { Forward CAATCAATGCCCCAGTCAC } \\
\text { Reverse GATTCTTGGGTTGTGGGAGTG }\end{array}$ \\
\hline Glut 4 & $\begin{array}{l}\text { Forward ATGACTGTGGCTCTGCTCCT } \\
\text { Reverse AAGATGGCCACAATGGAGAC }\end{array}$ \\
\hline FABP4 & $\begin{array}{l}\text { Forward AACTGAACTCAGGGGGACCT } \\
\text { Reverse TCCATTGTCTGTCCGTTTGA }\end{array}$ \\
\hline HSL & $\begin{array}{l}\text { Forward ACCTGCGCACAATGACACA } \\
\text { Reverse TGGCTCGAGAAGAAGGCTATG }\end{array}$ \\
\hline PPARG & $\begin{array}{l}\text { Forward CACGGAACACGTGCAGCTA } \\
\text { Reverse GGAGCGGGTGAAGACTCATG }\end{array}$ \\
\hline Leptin & $\begin{array}{l}\text { Forward GAACCCTGTGCGGATTCTTGT } \\
\text { Reverse TCCATCTTGGATAAGGTCAGGAT }\end{array}$ \\
\hline TNF- $\alpha$ & $\begin{array}{l}\text { Forward CGAGTGACAAGCCTGTAGC } \\
\text { Reverse GGTGTGGGTGAGGAGCACAT }\end{array}$ \\
\hline IL-6 & $\begin{array}{l}\text { Forward CCTGCAAGACCATCGACATG } \\
\text { Reverse CTGGCGAGCCTTAGTTTGGA }\end{array}$ \\
\hline TSP1 & $\begin{array}{l}\text { Forward TGTGAAAAGATGGAGAATGCTG } \\
\text { Reverse TTG TGGCCAATGTAGTTAGTGC }\end{array}$ \\
\hline GAPDH & $\begin{array}{l}\text { Forward AACAGCGACACCCATCCTC } \\
\text { Reverse CATACCAGGAAATGAGCTTGACAA }\end{array}$ \\
\hline
\end{tabular}
Foster City, CA, USA) according to the manufacturer's instructions. For quantification of gene expression, real-time PCR was conducted using SYBR ${ }^{\circledR}$ Green PCR Master Mix (Applied Biosystems, Foster City, USA) on an Applied Biosystems 7900 real-time PCR system (Applied Biosystems). Each sample was normalized to GAPDH. The relative expression of mRNAs was quantified by $2^{-\Delta c t}$ with logarithm transformation. The forward and reverse primers are shown in Table 2.

\section{microRNA detection}

miR-221 was quantified using a TaqMan microRNA detection assay (Applied Biosystems) and miR221 specific primer sets were supplied by Applied Biosystems. Expression level of miR-221 in each sample was normalized to the corresponding level of U6B. The relative expression of miRNAs was quantified by $2^{-\Delta \mathrm{ct}}$ with logarithm transformation.

\section{microRNA Transfection}

The Ambion ${ }^{\circledR}$ Pre-miR ${ }^{\mathrm{TM}}$ miRNA Precursor (PM10337) and Pre-miR ${ }^{\mathrm{TM}}$ miRNA Precursor Molecules Negative Control (AM17110) were purchased from Applied Biosystems. They were transfected into hASCs at a final concentration of $100 \mathrm{nM}$ using Oligofectamine ${ }^{\mathrm{TM}}$ transfection reagent (Life Technologies, CA, USA) according to the manufacturer's instructions. 
Enzyme-linked immunosorbent assay (ELISA)

The protein levels of IL-6, IL-8 and MCP-1 were measured using the 0ptEIA human IL-6, IL-8 and MCP-1 ELISA kit (BD Biosciences Pharmingen, San Diego, USA). Briefly described, the supernatant samples were plated in duplicate wells of a 96-well plate. Freshly diluted IL-6, IL-8 and MCP-1 were used to generate a standard curve. The absorbance at $450 \mathrm{~nm}$ was detected by a spectrophotometric plate reader (Bio Rad Benchmark Plus). Raw data were corrected against blank wells and converted to $\mathrm{pg} / \mathrm{ml}$ using the standard curve.

\section{Statistical analysis}

Data of a continuous variable was expressed as the mean \pm SD. The unpaired t-test was used to compare the means between two groups. A P value less than 0.05 was considered statistically significant. Correlation coefficient (R) was performed by the JMP software (version 9).The functional annotation of a gene in relation to miR-221 was performed using Ingenuity Pathways Analysis (IPA; Ingenuity Systems, Redwood City, CA, www.ingenuity.com).

\section{Results}

Changes of miR-221 levels during adipogenic differentiation of hASCs

The entire process normally takes 12 days for hASCs to differentiate to mature adipocytes. To detect the formation of adipocytes we used Oil Red 0 stain for the intracellular lipid droplets. We found that miR-221 expression levels in hASCs decreased over time during the process of adipogenic differentiation regardless of whether the hASCs were derived from obese or lean subjects (Fig. 1A). However, miR-221 levels were significantly lower in the samples derived from obese subjects than from lean subjects on days 8 and 12 of differentiation (Fig. 1A). Based on the results of Oil Red O stain, the hASC-differentiated adipocytes from obese women had better differentiation than those from lean subjects on days 12 (Fig. 1B). On day 12, two differentiation markers (GLUT4 and PPARG) were checked for the relationship between the adipogenic differentiation status and miR-221 level. The results indicated strong, inverse correlations between miR-221 levels and both markers (correlation coefficient was -0.90 for GLUT4, -0.94 for PPARG, Fig. 1C).

\section{The effect of miR-221 on lipid accumulation}

Given that miR-221 levels decreased while hASCs differentiated to mature adipocytes, we further investigated the effect of miR-221 on lipid accumulation during adipocyte differentiation. Two days before the induction of differentiation, pre-miR-221 was transfected into hASCs (Fig. 2A). On day 12, the intracellular miR-221 level in the cells transfected with pre-miR-221 was still higher than that in the cells transfected with the negative control by $\sim 100$-fold. Transfection of pre-miR-221 slightly reduced lipid accumulation in hASCdifferentiated adipocytes from the obese subjects on day 12 as indicated by Oil Red 0 stain (Fig. 2B). However, pre-miR-221 had almost no effect on the lipid content of hASCdifferentiated adipocytes derived from lean subjects (Fig. 2B). Using the optical density to quantify the amount of intracellular lipid, transfected pre-miR-221 was found to decrease the amount of accumulated lipid by $\sim 20 \%$ in the hASC-differentiated adipocytes from obese subjects (Fig. 2C). Transfection of pre-miR-221 partly caused reductions of the mRNA levels of four differentiation markers (GLUT4, HSL, PPARG and fatty acid binding protein 4 (FABP4)) by 10\% 20\% in obese subjects. However, only GLUT4 of the reductions reached a significant level (Fig. 2D).

miR-221 affects cytokine and adipokine levels in hASC-differentiated adipocytes from obese subjects

Since TNF- $\alpha$, leptin and TSP1 were predicted to be target genes of miR-221 in the miRWalk database [34], we measured their mRNA levels in hASC-differentiated adipocytes transfected with pre-miR-221. Our experiments showed that pre-miR-221 treatment 
Chou et al.: Decreased MicroRNA-221 is Associated with High Levels of TNF- $\alpha$

Fig. 1. Changes of miR-221 levels during adipogenic differentiation of hASC. hASCs were induced for adipogenic differentiation by the adipogenic medium and cells were harvested on days $0,1,4,8,12$ during differentiation. MiR221 levels were measured by real-time PCR and normalized to U6B. Each hASC sample was performed in duplication. (A) The differences between cells derived from lean $(n=4)$ and obese $(n=4)$ females were significant on day 8 and day 12. *indicates $\mathrm{P}<0.05$ when compared to the level on day 0 ; " indicates $\mathrm{P}<0.05$ between hASCs derived from obese and lean subjects. (B) Lipid droplets were visualized by Oil Red-O staining from representative hASC differentiation. Lipid droplets were quantified in isopropanol extracts by using the optical density (four obese and two lean subjects). *indicates $\mathrm{P}<0.05$ when compared to the lean subjects. (C) Inverse correlations between miR-221 and GLUT4 and PPARG mRNAs during hASC differentiation of four obese women. On the X axis, miR-221 levels are expressed as $\log _{10} 2^{-\Delta \mathrm{Ct}}$ and $\Delta \mathrm{Ct}=\mathrm{Ct}(\mathrm{miR}-$ 221)-Ct(U6B). The $Y$ axis similarly represents mRNA levels as $\log _{10} 2^{-\Delta C t}$ but $\Delta \mathrm{Ct}=\mathrm{Ct}$ (gene)Ct(GAPDH).

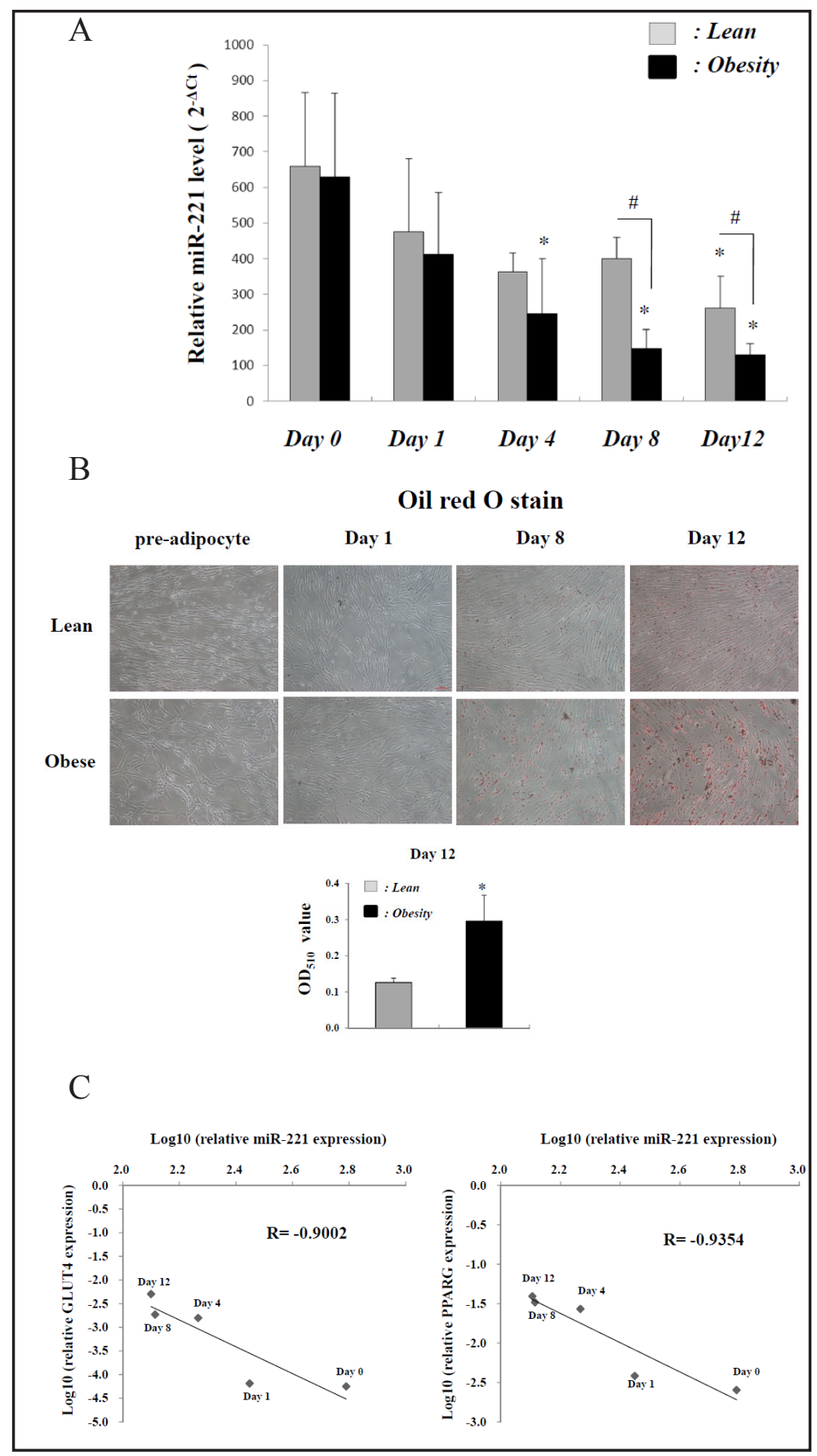

significantly reduced TNF- $\alpha$ mRNA level by $50 \%$ (Fig. 3A, left), and had a weaker effect on leptin and TSP1 (both adipokines were inhibited by approximately 20\%, Fig. 3C). We then tested whether an increase of miR-221 level can influence pro-inflammatory cytokines including IL-6, IL-8 and MCP-1. Noticeably, these cytokines were not predicted to be miR221 's direct targets. Our data showed that pre-miR-221 treatment slightly decreased MCP-1 mRNA levels by $\sim 10 \%$ (Fig. 3A, middle) but did not have any effect on IL-6 mRNA levels. Using the ELISA assay, miR-221 did not cause any change of MCP-1 protein level (Fig. 3A, right) but reduced IL-6 protein levels (Fig. 3B, left). For IL-8, miR-221 had no effect on either mRNA or protein levels (Fig. 3B, right). 


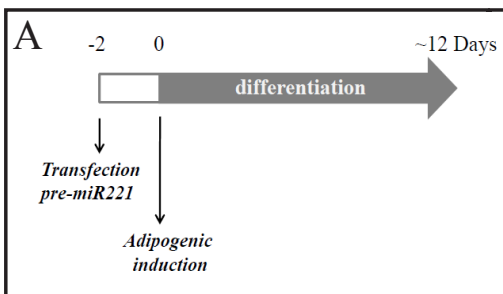

Fig. 2. Transfection of premiR-221 hASC to assess the effect of miR-221 on lipid accumulation. (A) hASCs from four obese women were transfected with pre-miR-221 at 48 hours before the induction of adipogenic differentiation. (B) Intracellular lipid droplets on day 12 were observed under a light microscopy and detected by Oil Red 0 stain. The upper panel shows the results from cells transfected with negative control (100 nM) and bottom panel from cells transfected with pre-miR-221 (100 nM). A representative phase contrast images are observed with $200 \mathrm{X}$ magnification. (C) Lipid droplets were quantified in isopropanol extracts by using the optical density. (D) hASCs transfected with pre-miR-221 were subject to differentiation. On day 12 of differentiation, the expression levels of GLUT4, PPARG, HSL and FABP4 mRNA were measured by RT-qP$\mathrm{CR}$ and normalized to GAPDH. We used four obese hASC samples for each experiment and performed the duplicate experiment for each sample.

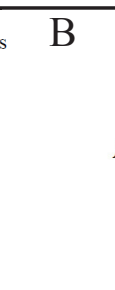

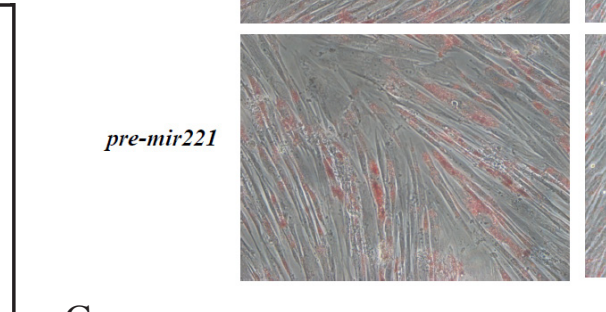
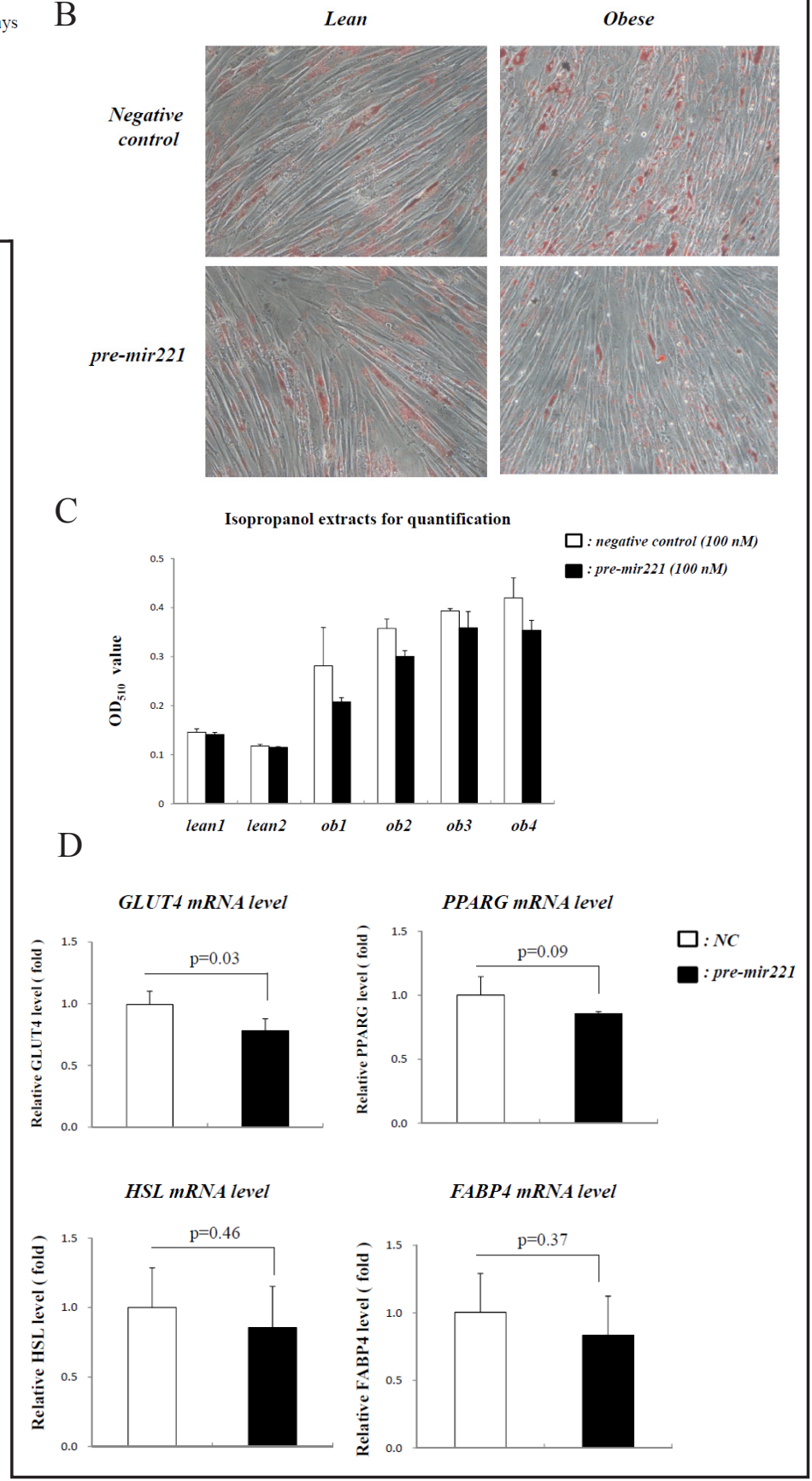

Difference of miR-221 and adipokines expression levels between obese and lean subjects

We further investigated whether the relationships between miR-221 levels and adipokines are different between hASC-differentiated adipocytes from obese women $(B M I>30, n=4)$ and those from lean women $(B M I<24, n=4)$ women (Table 1). The Figure $1 \mathrm{~A}$ showed that miR-221 levels were significantly lower in the hASC-differentiated adipocytes from obese subjects than those from lean subjects. On the contrary, the mRNA levels of TNF- $\alpha$, leptin and TSP1 were higher in the hASC-differentiated adipocytes from obese women than those from lean women (Fig. 4A). Analyzing the total of 8 samples, we found an inverse correlation between TNF- $\alpha$ and miR-221 levels with a correlation coefficient of -0.90 (Fig. 4B), as well as a negative relationship between miR-221 levels and BMI with a correlation coefficient of -0.75 (Fig. 4C). 
Fig. 3. miR-221 modulates proinflammatory cytokines and adipokines in obese hASCs. hASCs transfected with pre-miR-221 were subject to differentiation. On day 12 of differentiation, (A) the expression levels of TNF- $\alpha$ and MCP-1, (B) the expression levels of IL-6 and IL-8, and (C) the mRNA expression levels of leptin and TSP1 were analyzed. mRNA were measured by RT-qPCR and normalized to GAPDH. Protein levels were measured by ELISA. We used four obese hASC samples for each experiment and performed the duplicate experiment for each sample. $*$ indicates $P<0.05$.

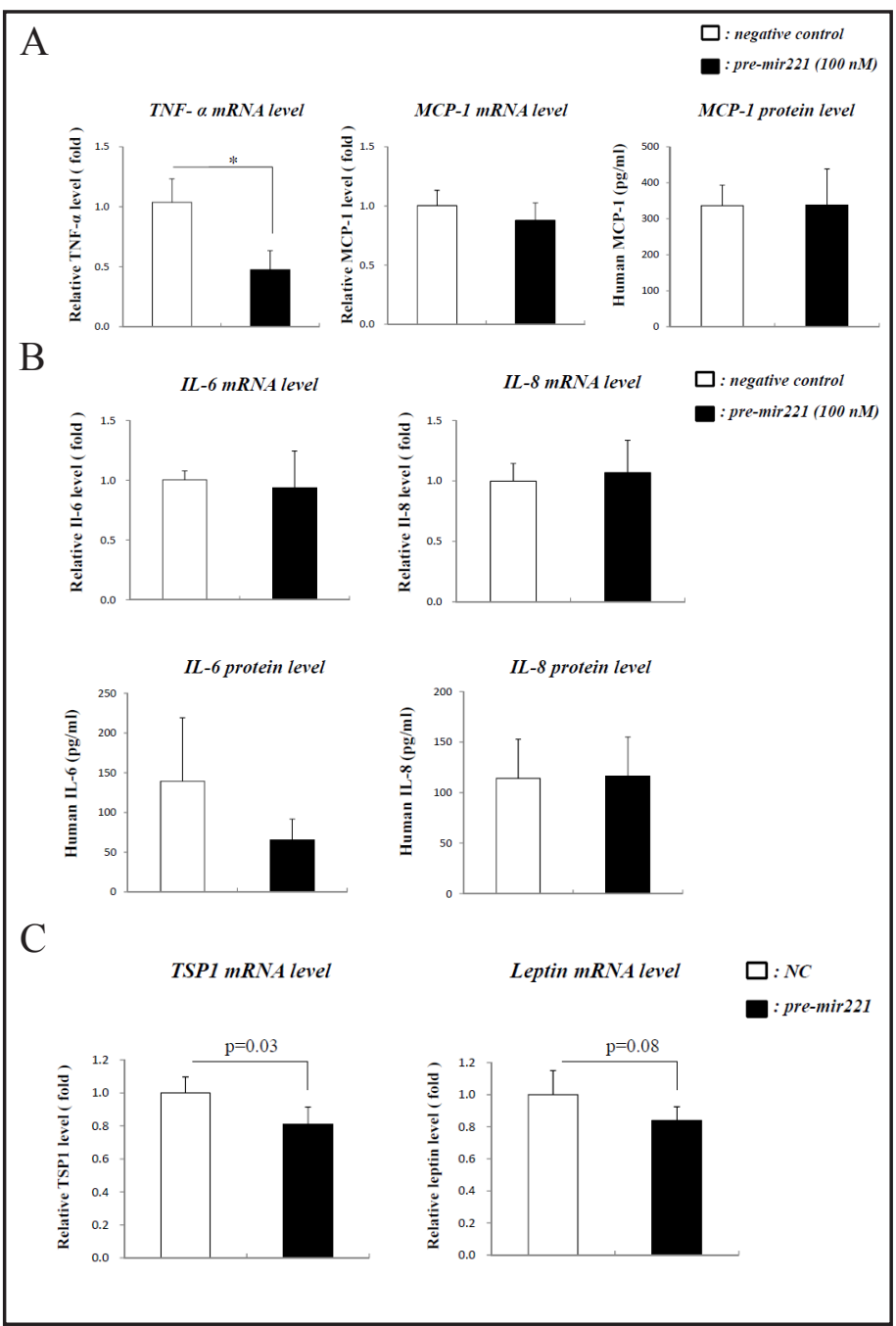

\section{Discussion}

The present study showed that miR-221 was significantly down-regulated during adipogenesis of hASCs. Interestingly, even though the adipogenesis experiment was conducted in vitro, miR-221 levels were lower in hASC-differentiated adipocytes from obese subjects than those from lean subjects. Our studies demonstrated that over-expression of miR-221 could reduce TNF- $\alpha$ expression in adipocytes. A possible explanation for this phenomenon is that miR-221 directly knocks down TNF- $\alpha$ mRNA. The hASC-differentiated adipocytes from obese female subjects had higher TNF- $\alpha$ mRNA levels but lower miR-221 levels. In addition, miR-221 levels were also inversely correlated with BMI, indicating a link between the severity of obesity and miR-221 levels. Therefore, this study shows that miR221 could potentially prevent inflammation in obese women.

The down-regulation pattern of miR-221 shown in our human samples during adipogenesis was consistent with the findings from the adipogenesis of 3T3-L1 and human subcutaneous fat cells $[10,35]$. An interesting finding of the present study was that miR221 could down-regulate the expression of TNF- $\alpha$ in adipocytes. TNF- $\alpha$ plays a crucial role in a variety of inflammatory diseases, and it also serves as a link between obesity and insulin resistance $[37,38]$. An elevated TNF- $\alpha$ expression has been documented in human abdominal subcutaneous adipose tissues of obese persons [39]. Previous studies have shown that TNF- $\alpha$ treatment could enhance the expression of miR-221 in 3T3-L1 adipocytes 


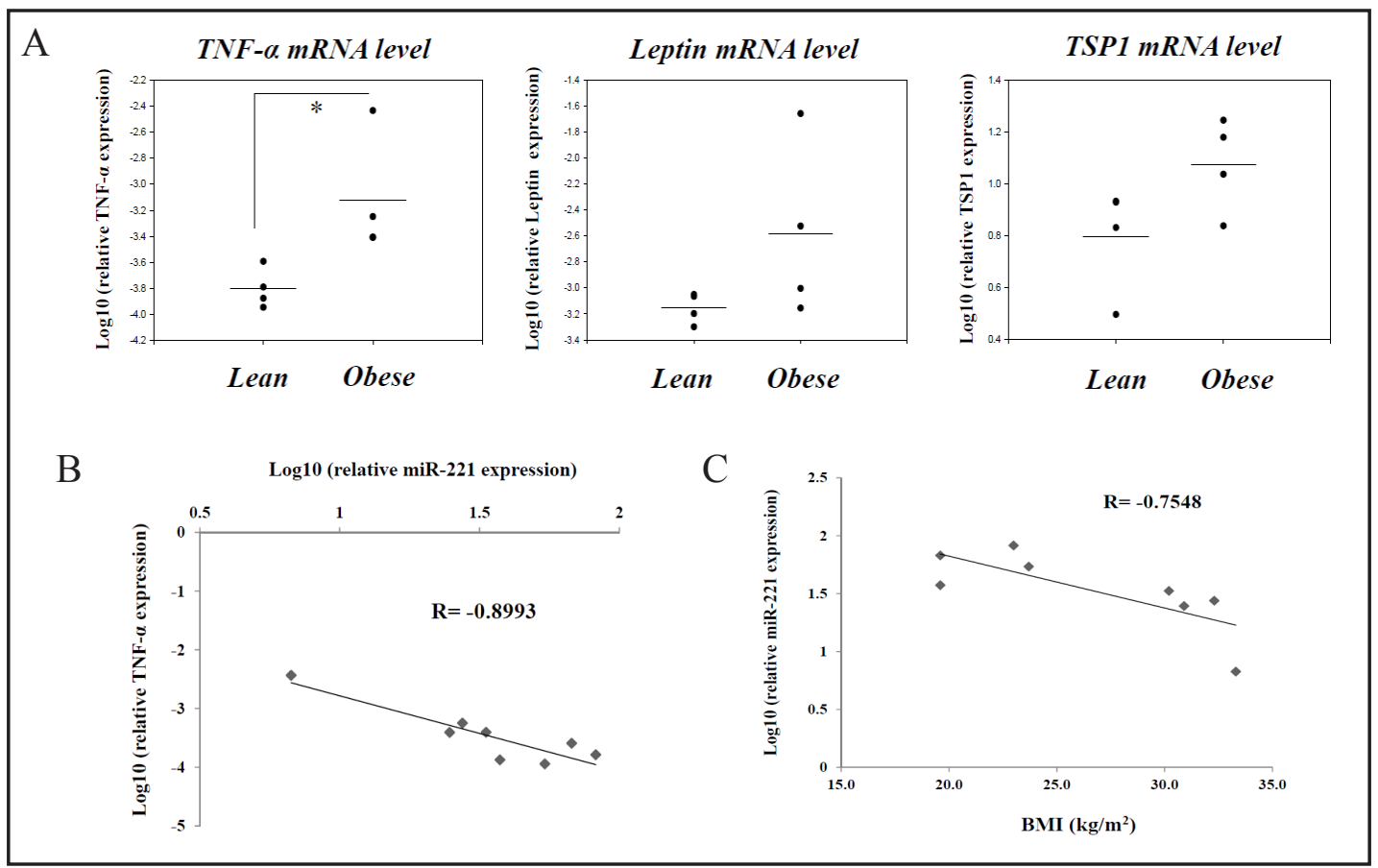

Fig. 4. Differential expression of miR-221 in lean and obese women. (A) On day 12 of differentiation, the levels of TNF- $\alpha$, leptin and TSP1 mRNA were measured by RT-qPCR analysis using GAPDH as the internal control. On the Y axis, TNF- $\alpha$, leptin and TSP1 levels are expressed as $\log _{10} 2^{-\Delta C t}$ whereas $\Delta \mathrm{Ct}=\mathrm{Ct}$ (gene)Ct(GAPDH). (B) Inverse correlation between TNF- $\alpha$ mRNA and miR-221. On the X axis, miR-221 levels are expressed as $\log _{10} 2^{-\Delta \mathrm{Ct}}$ and $\Delta \mathrm{Ct}=\mathrm{Ct}(\mathrm{miR}-221)-\mathrm{Ct}(\mathrm{U} 6 \mathrm{~B})$. The $\mathrm{Y}$ axis similarly represents mRNA levels as $\log _{10} 2^{-\Delta \mathrm{Ct}}$ but $\Delta \mathrm{Ct}=\mathrm{Ct}$ (gene)-Ct(GAPDH), and (C) Inverse correlation between miR-221 and BMI. We used eight different hASC samples for each experiment and performed the duplicate experiment for each sample. * indicates $P<0.05$.

[10]. Accordingly, there may be reciprocal regulation between miR-221 and TNF- $\alpha$ during adipogenesis. Additionally, the present study found that over-expression of miR-221 could reduce IL-6 concentration. The data from IPA analysis suggested that miR-221 can target STAT5A, which in turn affects NFKB, estrogen receptor alpha and CREB-bind protein to cause a change of IL- 6 expression level. Since both TNF- $\alpha$ and IL- 6 have been implicated in obesityrelated insulin resistance [39], over-expression of miR-221 could be a promising strategy to prevent obesity-induced insulin resistance.

The present study showed that the expression levels of miR-221 decreased more rapidly in differentiating hASCs from obese women than in those from lean women. Based on the data shown in figures $1 \mathrm{~B}$ and $2 \mathrm{C}$, the hASCs from obese women differentiated more efficiently. These results suggested that miR-221 may play a role in hASC differentiation. In addition, we showed that over-expression of miR-221 partly reduced lipid accumulation in the hASC-differentiated adipocytes from obese women but had no noticeable effect on those from lean women. Our data also suggested that miR-221 may reduce leptin and TSP1 mRNA levels because these adipokines are miR-221's target genes. TSP-1 deficiency can reduce obesity-associated inflammation and improve insulin resistance in a diet-induced obese mouse model [40]. These data suggested that miR-221 could have beneficial effects by interfering with inflammatory status and adipokine metabolism. However, the present study used a limited number of tissue samples due to our restricted selection criteria (females with either high or low BMI) and the difficulty associated with developing hASCs. Another limitation of our study is that we only transfected miR-221 but did not transfect anti-miR-221 to hASCs before adipogenic differentiation because of limited availability of hASCs. Therefore, future studies to replicate our results are warranted. 
Chou et al.: Decreased MicroRNA-221 is Associated with High Levels of TNF- $\alpha$

In summary, our data show down-regulation of miR-221 during hASC adipogenic differentiation. The decrease of miR-221 is more prominent in the hASC-differentiated adipocytes from obese women compared to those from lean women. MiR-221 levels are negatively associated with BMI and obesity related biomarkers. Therefore, miR-221 may serve as a novel target to prevent obesity and obesity-induced inflammatory diseases.

\section{Abbreviations}

hASCs (Human adipose tissue-derived mesenchymal stem cells); TNF- $\alpha$ (tumor necrosis factor-alpha); FABP4 (fatty acid binding protein 4); IL-6 (interleukin-6); GLUT4 (Glucose transporter type 4); HSL (Hormone-sensitive lipas); PPARG (peroxisome proliferator activated receptor $\gamma$ ); TSP1 (thrombospondin 1); BMI (body mass index).

\section{Conflict of Interest}

The authors declare that there are no conflicts of interest.

\section{Acknowledgements}

This study was supported by National Science Council, Taiwan (NSC 100-2923-B-037001-MY3), Academia Sinica (BM102021169), National Health Research Institutes, Taiwan (NHRI-Ex101-10107PI) and Kaohsiung Medical University Hospital intramural grant (KMUH101-1R57)

\section{References}

1 Schickel R, Boyerinas B, Park SM, Peter ME: Micrornas: Key players in the immune system, differentiation, tumorigenesis and cell death. Oncogene 2008;27:5959-5974.

2 Nelson P, Kiriakidou M, Sharma A, Maniataki E, Mourelatos Z: The microrna world: Small is mighty. Trends Biochem Sci 2003;28:534-540.

-3 Alvarez-Garcia I, Miska EA: Microrna functions in animal development and human disease. Development 2005;132:4653-4662.

4 Chen KC, Hank Juo SH: Micrornas in atherosclerosis. Kaohsiung J Med Sci 2012;28:631-640.

-5 Chen KC, Hsieh IC, Hsi E, Wang YS, Dai CY, Chou WW, Juo SH: Negative feedback regulation between microrna let-7g and the oxldl receptor lox-1. J Cell Sci 2011;124:4115-4124.

6 Dehwah MA, Xu A, Huang Q: Micrornas and type 2 diabetes/obesity. J Genet Genomics 2012;39:11-18.

7 Frost RJ, Olson EN: Control of glucose homeostasis and insulin sensitivity by the let-7 family of micrornas. Proc Natl Acad Sci U S A 2011;108:21075-21080.

8 Romao JM, Jin W, Dodson MV, Hausman GJ, Moore SS, Guan LL: Microrna regulation in mammalian adipogenesis. Exp Biol Med 2011;236:997-1004.

9 Kajimoto K, Naraba H, Iwai N: Microrna and 3t3-l1 pre-adipocyte differentiation. RNA 2006;12:1626-1632.

-10 Xie H, Lim B, Lodish HF: Micrornas induced during adipogenesis that accelerate fat cell development are downregulated in obesity. Diabetes 2009;58:1050-1057.

11 Ono K: Microrna links obesity and impaired glucose metabolism. Cell Res 2011;21:864-866.

12 Martinelli R, Nardelli C, Pilone V, Buonomo T, Liguori R, Castano I, Buono P, Masone S, Persico G, Forestieri P, Pastore L, Sacchetti L: Mir-519d overexpression is associated with human obesity. Obesity 2010;18:2170-2176.

13 Zuk PA, Zhu M, Ashjian P, De Ugarte DA, Huang JI, Mizuno H, Alfonso ZC, Fraser JK, Benhaim P, Hedrick MH: Human adipose tissue is a source of multipotent stem cells. Mol Biol Cell 2002;13:4279-4295. 


\section{Cellular Physiology $\quad$ Cell Physiol Biochem 2013;32:127-137 and Biochemistry \\ Chou et al.: Decreased MicroRNA-221 is Associated with High Levels of TNF- $\alpha$}

14 Rodriguez AM, Elabd C, Amri EZ, Ailhaud G, Dani C: The human adipose tissue is a source of multipotent stem cells. Biochimie 2005;87:125-128.

-15 Esau C, Kang X, Peralta E, Hanson E, Marcusson EG, Ravichandran LV, Sun Y, Koo S, Perera RJ, Jain R, Dean NM, Freier SM, Bennett CF, Lollo B, Griffey R: Microrna-143 regulates adipocyte differentiation. J Biol Chem 2004;279:52361-52365.

16 Xu N, Papagiannakopoulos T, Pan G, Thomson JA, Kosik KS: Microrna-145 regulates oct4, sox2, and klf4 and represses pluripotency in human embryonic stem cells. Cell 2009;137:647-658.

$\checkmark 17$ Lee EK, Lee MJ, Abdelmohsen K, Kim W, Kim MM, Srikantan S, Martindale JL, Hutchison ER, Kim HH, Marasa BS, Selimyan R, Egan JM, Smith SR, Fried SK, Gorospe M: Mir-130 suppresses adipogenesis by inhibiting peroxisome proliferator-activated receptor gamma expression. Mol Cell Biol 2011;31:626-638.

18 Schenk S, Saberi M, Olefsky JM: Insulin sensitivity: Modulation by nutrients and inflammation. J Clin Invest 2008;118:2992-3002.

19 Neels JG, Olefsky JM: Inflamed fat: What starts the fire? J Clin Invest 2006;116:33-35.

20 Cawthorn WP, Sethi JK: Tnf-alpha and adipocyte biology. FEBS Lett 2008;582:117-131.

21 Katsuki A, Sumida Y, Murashima S, Murata K, Takarada Y, Ito K, Fujii M, Tsuchihashi K, Goto H, Nakatani $\mathrm{K}$, Yano Y: Serum levels of tumor necrosis factor-alpha are increased in obese patients with noninsulindependent diabetes mellitus. J Clin Endocrinol Metab 1998;83:859-862.

22 Bastard JP, Jardel C, Bruckert E, Blondy P, Capeau J, Laville M, Vidal H, Hainque B: Elevated levels of interleukin 6 are reduced in serum and subcutaneous adipose tissue of obese women after weight loss. J Clin Endocrinol Metab 2000;85:3338-3342.

23 Straczkowski M, Dzienis-Straczkowska S, Stepien A, Kowalska I, Szelachowska M, Kinalska I: Plasma interleukin-8 concentrations are increased in obese subjects and related to fat mass and tumor necrosis factor-alpha system. J Clin Endocrinol Metab 2002;87:4602-4606.

-24 Sato M, Miyazaki T, Nagaya T, Murata Y, Ida N, Maeda K, Seo H: Antioxidants inhibit tumor necrosis factoralpha mediated stimulation of interleukin-8, monocyte chemoattractant protein-1, and collagenase expression in cultured human synovial cells. J Rheumatol 1996;23:432-438.

25 Hu CJ, Lee YL, Shih NY, Yang YY, Charoenfuprasert S, Dai YS, Chang SM, Tsai YH, Tseng H, Liu CY, Leu SJ: Reduction of monocyte chemoattractant protein-1 and interleukin-8 levels by ticlopidine in tnf-alpha stimulated human umbilical vein endothelial cells. J Biomed Biotechnol 2009;2009:917837.

-26 Kirchgessner TG, Uysal KT, Wiesbrock SM, Marino MW, Hotamisligil GS: Tumor necrosis factor-alpha contributes to obesity-related hyperleptinemia by regulating leptin release from adipocytes. J Clin Invest 1997;100:2777-2782.

27 Finck BN, Johnson RW: Tumor necrosis factor (tnf)-alpha induces leptin production through the p55 tnf receptor. Am J Physiol Regul Integr Comp Physiol 2000;278:R537-543.

28 Salajegheh M, Raju R, Schmidt J, Dalakas MC: Upregulation of thrombospondin-1(tsp-1) and its binding partners, cd36 and cd47, in sporadic inclusion body myositis. J Neuroimmunol 2007;187:166-174.

29 Narizhneva NV, Razorenova OV, Podrez EA, Chen J, Chandrasekharan UM, DiCorleto PE, Plow EF, Topol EJ, Byzova TV: Thrombospondin-1 up-regulates expression of cell adhesion molecules and promotes monocyte binding to endothelium. FASEB J 2005;19:1158-1160.

- 30 Considine RV, Sinha MK, Heiman ML, Kriauciunas A, Stephens TW, Nyce MR, Ohannesian JP, Marco CC, McKee LJ, Bauer TL, et al.: Serum immunoreactive-leptin concentrations in normal-weight and obese humans. N Engl J Med 1996;334:292-295.

-31 Maffei M, Halaas J, Ravussin E, Pratley RE, Lee GH, Zhang Y, Fei H, Kim S, Lallone R, Ranganathan S, et al.: Leptin levels in human and rodent: Measurement of plasma leptin and ob rna in obese and weight-reduced subjects. Nat Med 1995;1:1155-1161.

- 32 Varma V, Yao-Borengasser A, Bodles AM, Rasouli N, Phanavanh B, Nolen GT, Kern EM, Nagarajan R, Spencer HJ 3rd, Lee MJ, Fried SK, McGehee RE Jr, Peterson CA, Kern PA: Thrombospondin-1 is an adipokine associated with obesity, adipose inflammation, and insulin resistance. Diabetes 2008;57:432-439.

33 El Gazzar M, McCall CE: Micrornas distinguish translational from transcriptional silencing during endotoxin tolerance. J Biol Chem 2010;285:20940-20951.

34 Dweep H, Sticht C, Pandey P, Gretz N: Mirwalk--database: Prediction of possible mirna binding sites by "walking" the genes of three genomes. J Biomed Inform 2011;44:839-847. 


\section{Cellular Physiology $\quad$ Cell Physiol Biochem 2013;32:127-137 and Biochemistry

-35 Ortega FJ, Moreno-Navarrete JM, Pardo G, Sabater M, Hummel M, Ferrer A, Rodriguez-Hermosa JI, Ruiz B, Ricart W, Peral B, Fernandez-Real JM: Mirna expression profile of human subcutaneous adipose and during adipocyte differentiation. PloS one 2010;5:e9022.

36 Liao YC, Chou WW, Li YN, Chuang SC, Lin WY, Lakkakula BV, Yu ML, Juo SH: Apelin gene polymorphism influences apelin expression and obesity phenotypes in chinese women. Am J Clin Nutr 2011;94:921-928.

37 Ruan H, Lodish HF: Insulin resistance in adipose tissue: Direct and indirect effects of tumor necrosis factoralpha. Cytokine Growth Factor Rev 2003;14:447-455.

- 38 Lorenzo M, Fernandez-Veledo S, Vila-Bedmar R, Garcia-Guerra L, De Alvaro C, Nieto-Vazquez I: Insulin resistance induced by tumor necrosis factor-alpha in myocytes and brown adipocytes. J Anim Sci 2008;86:E94-104.

39 Kern PA, Ranganathan S, Li C, Wood L, Ranganathan G: Adipose tissue tumor necrosis factor and interleukin-6 expression in human obesity and insulin resistance. Am J Physiol Endocrinol Metab 2001;280:E745-751.

40 Li Y, Tong X, Rumala C, Clemons K, Wang S: Thrombospondin1 deficiency reduces obesity-associated inflammation and improves insulin sensitivity in a diet-induced obese mouse model. PloS One 2011;6:e26656. 